\title{
INVESTIGATION OF FLUID STREAM OSCILLATION INSIDE RESONATOR OF A WIND INSTRUMENT WITH THE USE OF HYDRODYNAMIC TABLE
}

\author{
Markéta PETŘíKOVÁ, Pavel PEUKERT, Jiří UNGER•
}

\begin{abstract}
The paper deals with the investigation of processes inside a general resonator of a woodwind instrument, with the use of a unique hydrodynamic table. Via the hydrodynamic analogy could be done estimations on some properties of a real system.
\end{abstract}

\section{INTRODUCTION}

Some processes are hard to investigate on models or real objects with the real medium, especially if it is air or another gas. In this case could be advantageous to choose an experimental approach with the usage of liquids. A lot of scientists had that idea in the past and they used a quasi-two-dimensional flow of liquid to simulate two-dimensional flow of gases. Some of them noticed not only a similarity of the flow, but also a real relationship between some conditions of the liquid layer to the two-dimensional gas flow conditions. This similarities and relationships are written down in the so called hydrodynamic analogy. One of the advantages of the experimental method is a very illustrative way of analog solutions while the complexity of initial and boundary conditions does not matter much. Also attractive is the fact that the flow process running in a larger time scale, which resulting from a low speed of wave propagation on the liquid surface in comparison with the sound speed in gases. A detailed description about the methodology is published by Nožička [1] and Merzkirch [3], also the thesis of Šidlof [2] use this approach.

\section{EXPERIMENT}

The experimental part of the work was done on the unique hydrodynamic table (Fig. 1), which allows visualization of two-dimensional flow of the liquid. The field of interest was the observation of the self-excited oscillation of the stream, which was caused by a continuous steady water flow into the specific cavity, the resonator. In Figure 2 is shown on the left side a woodwind instrument and on the right the model which should quite simulate such instrument.

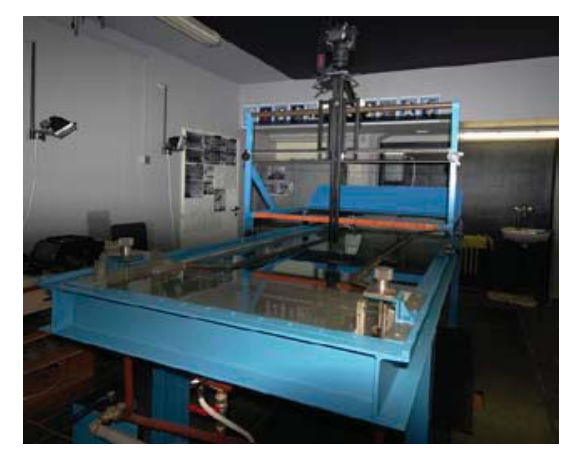

Figure 1: Hydrodynamic table.

\footnotetext{
- Markéta Petř́ková, Department of Power Engineering Equipment, Faculty of Mechanical Engineering, Technical University of Liberec, Studentská 2, 46117 Liberec 1, Czech republic marketa.petrikova@tul.cz
} 

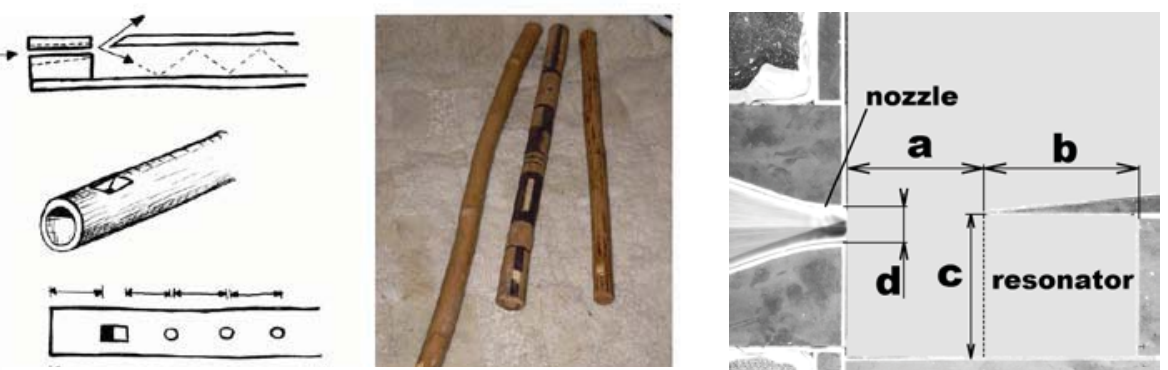

Figure 2: Woodwind instrument (left), the 2-D model (right)

The model is sized with the regard to visualize optimally the processes of the phenomena. For all experiments was used the same resonator width $c=20 \mathrm{~mm}$ and nozzle outlet width $d=92 \mathrm{~mm}$. The gap size between the nozzle and the resonator $a$, was 140 or $70 \mathrm{~mm}$ and the resonator depth $b$ vary in a ratios of $b / a, 1 / 2=0.5,1 / 1=1$, $2 / 1=2$ and $3 / 1=3$ which could be later seen in the Figure 5,6 . The model was located on the hydrodynamic table where a specific flow-rate was let inside the nozzle. The liquid film surface was at the inlet coated with contrasting colour particles for further visualization of the flow. The pictures of the flow were taken by a photo camera. Such a visualization set is shown in Figure 3. With the evaluation of the pictures were chosen the right measurement sites, for the liquid level height which later permit an estimation of the pressure-water level analogy explained later and the measurement of oscillation frequencies via a contact sensor. The methodology of the level height and oscillation frequencies is assumed by Petř́ková [4].
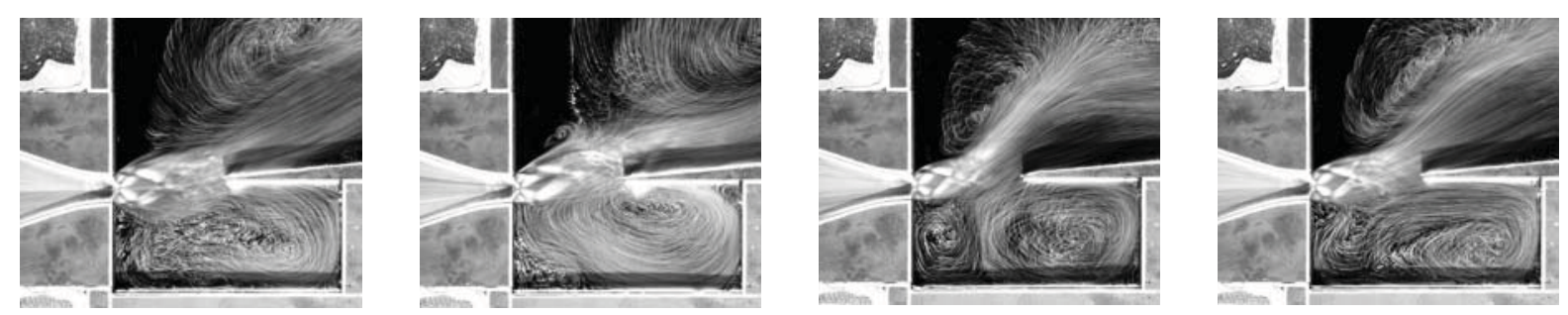

Figure 3: Two-dimensional visualization of the stream which oscillate in and out-wards of the resonator

\section{RESULTS}

In Figure 4 could be seen chart of dependence of oscillation frequencies on a diferent characterics dimension and flow rates. These results were directly obtained via a counter which follow the contact sensor. The characteristic dimension $D$ is defined as the sum of the dimension between resonator and nozzle outlet and the resonator depth $D=a+b$.

The charts in Figure 5 represent the relationship betwen the Strouhal's number and the pressure difference between nozzle outlet and the "far" outlet which have the function of atmospheric pressure. So it indicates direct the energetic level of the inlet stream. The Strouhal's number is defined as: $S h=D * f / w$, where $D$ is upper mentioned characteristic dimension, $f$ - oscillation frequency and $w$ - inlet velocity. In the charts of Figure 6 . is displayed the relation between Strouhal's and Reynold's number for different ratios. The Reynold's number is defined as: $R e=d * w / v$, where $d$ is the characteristic dimension of the nozzle at the outlet, $w$ the - outlet velocity of the nozzle and $v$ - kinematic viscosity. 

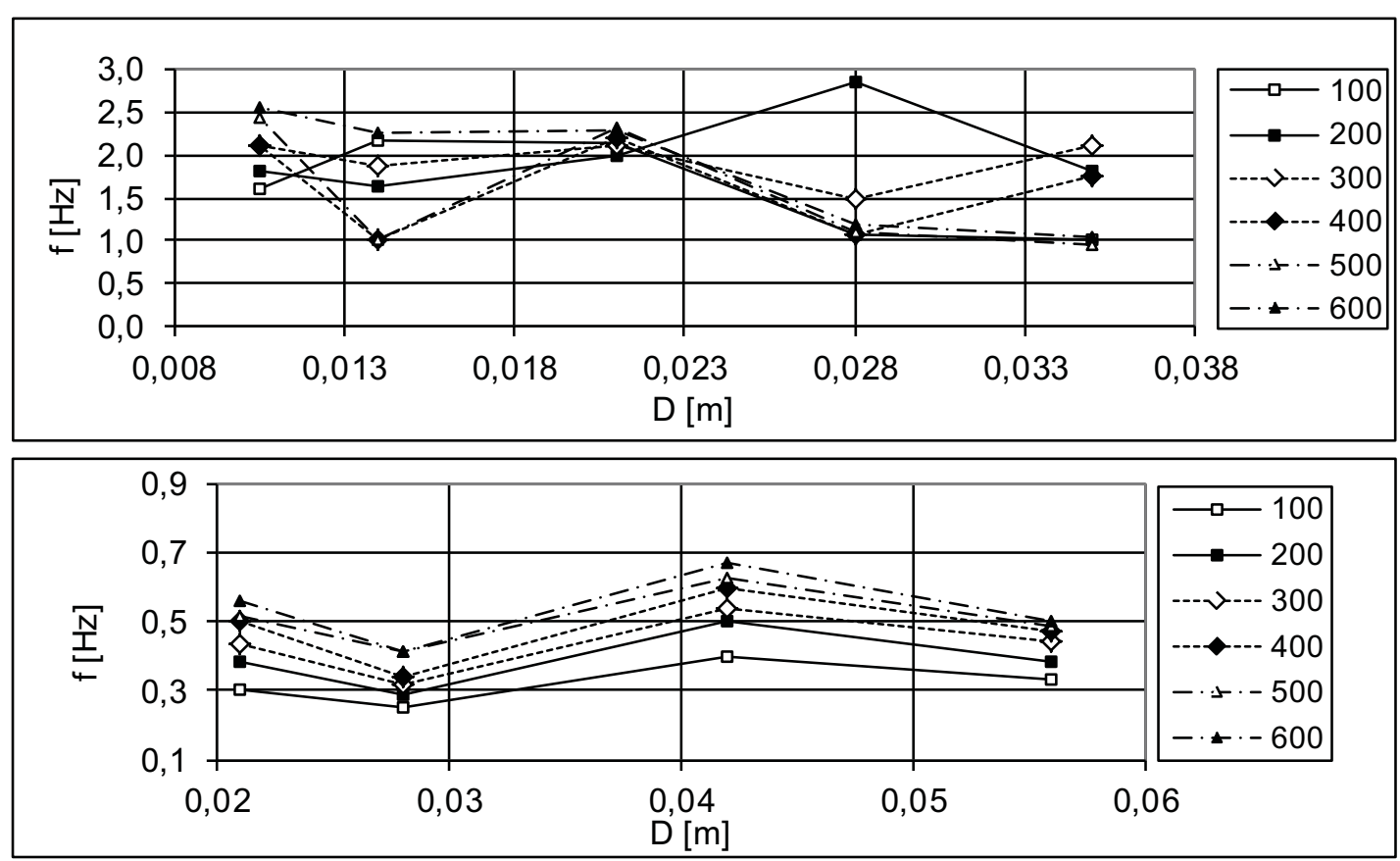

Figure 4: Dependence between the oscillation frequency and the characteristic dimension $D[\mathrm{~m}]$ for the gap $a=7[\mathrm{~cm}]$ (upper chart) and $a=14[\mathrm{~cm}]$ (lower chart) and different volumetric flow-rates from 100 to 600 litre per hour.
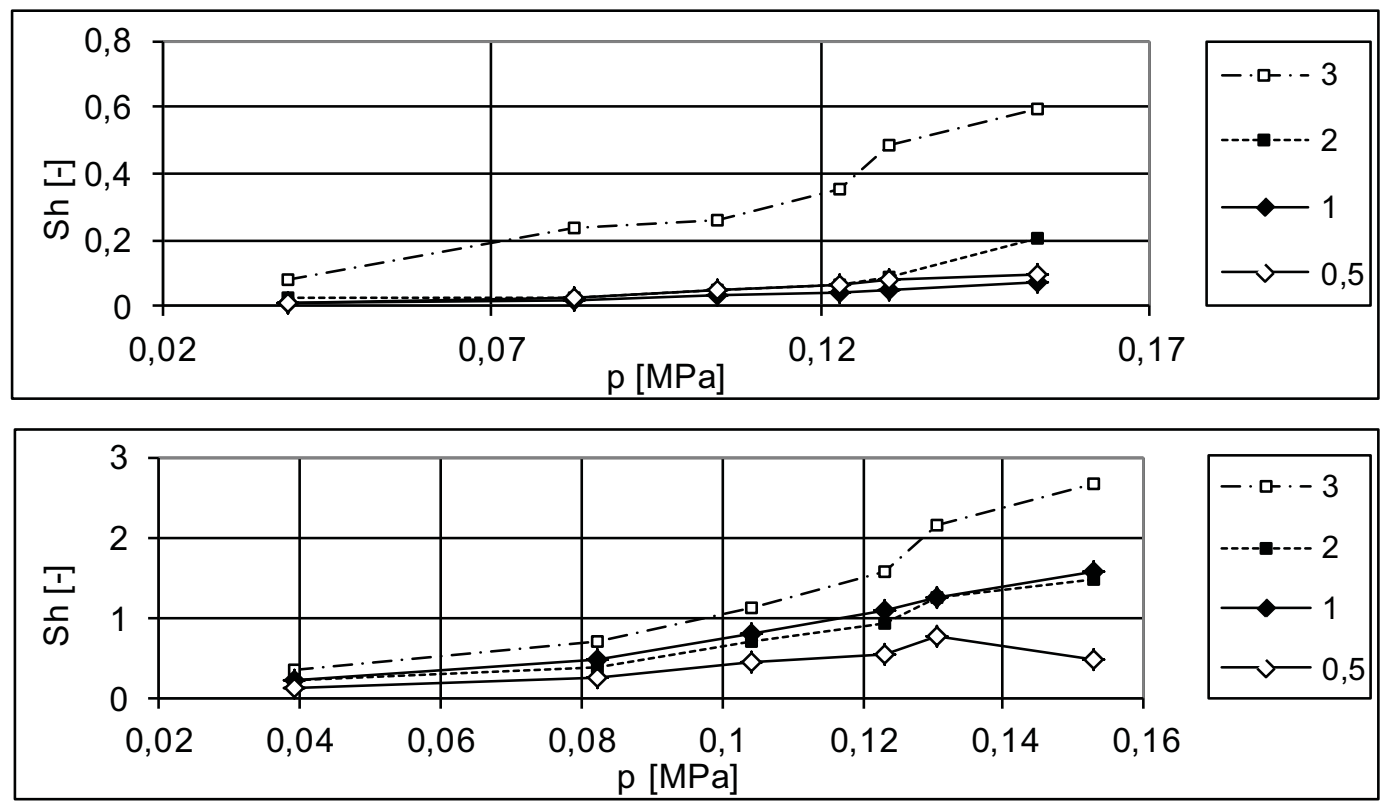

Figure 5: Dependence of Strouhal's number Sh [-] on the pressure difference $p[\mathrm{MPa}]$ for the $a=7[\mathrm{~cm}]$ (upper chart) and $a=14[\mathrm{~cm}]$ (lower chart) gap and for different ratios of $b / a$ 

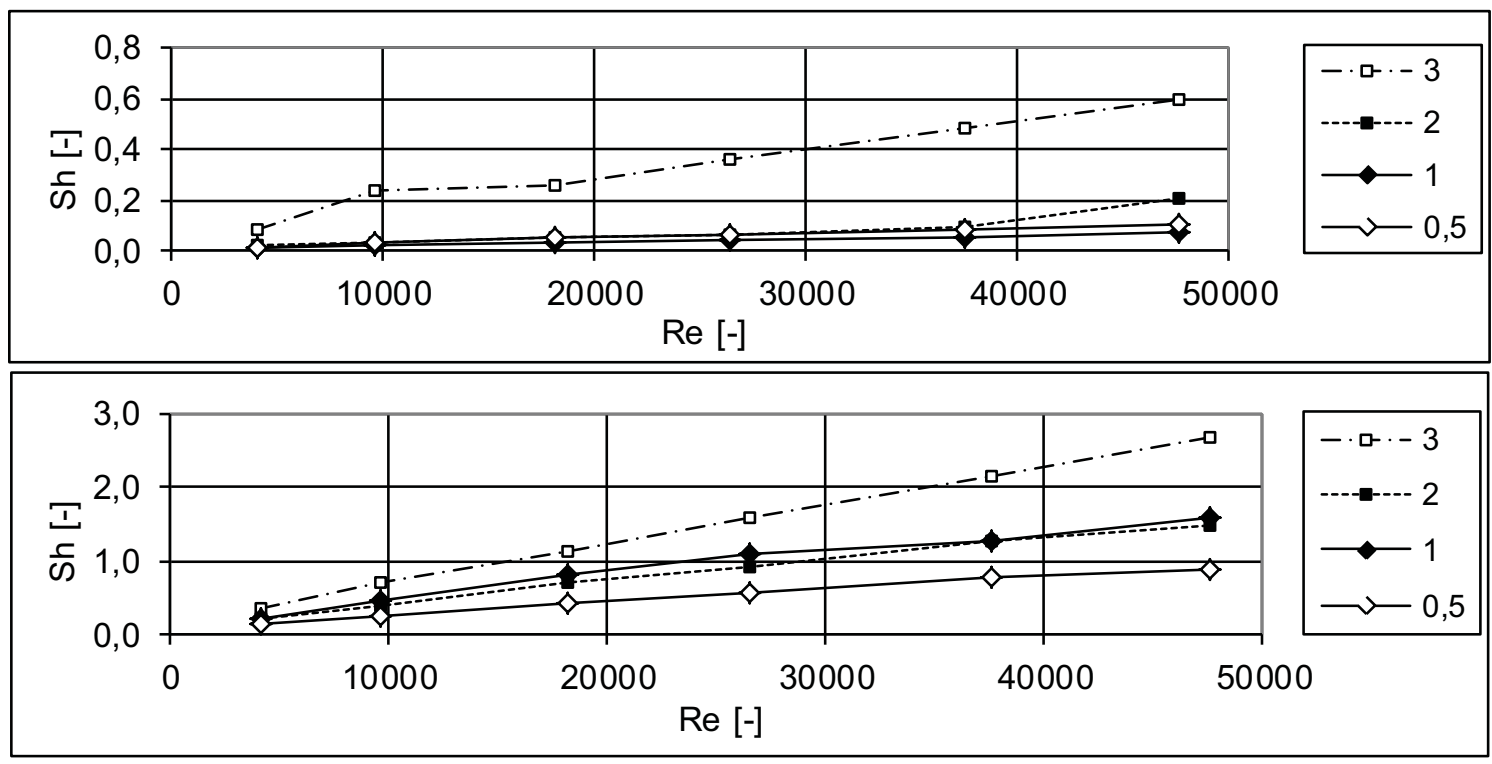

Figure 6: Dependence of Strouhal's number on Reynold's number for the gap $a=7[\mathrm{~cm}]$ (upper chart) and $a=14[\mathrm{~cm}]$ (lower chart).

\section{Conclusions}

The charts in Fig. 4 present an analogy between the flow of air and water given by the hydrodynamic analogy. In air that means aliquot tones, which are a line of tones with multiple frequency with the comparison of the keynote. The turns in the charts make visible that also in water under some conditions by repeating dimensions some local frequency maximum occurs. This knowledge could be used by designing of devices with self-dosage without any other impulses. The rising tendency in the charts in Figure 5, shows that the Strouhal's number is direct proportional to the overpressure.

As a verification of the measurements could be used charts in Figure 6 . The rising tendency corresponds to the predictions from the theory.

Discrepancies in charts could be found in cases with really low depths of resonators, typical with ratio of 0.5 , because a periodical oscillation could be hard achieved.

At least the experiment had shown that for tone generation it is not necessary to have a periodical forced supply, only the energy loses by damping have to by covered.

\section{ACKNOWLEDGEMENT}

The authors gratefully acknowledge the support by the project MSM 4674788501.

\section{REFERENCES}

[1] NOŽIČKA J.: Analogové metody v proudění, Academia Praha, Praha, 1967, p. 202

[2] ŠIDLOF P.: Použití hydrodynamické analogie pro výzkum výměny obsahu válců spalovacích motorů, Thesis, Vysoká škola strojní a textilní v Liberci, Fakulta strojní, Liberec, 1972

[3] MERZKIRCH W.: Flow visualization, Academic press, New York and London, 1974, p. 250, ISBN-0-12-491350-4

[4] PETŘÍKOVÁ M., KNEŘ J., JERJE P.: Snímač hladiny elektricky vodivé kapaliny, zejména výšky hladiny a frekvence jejího kmitání, Osvědčení o zápisu užitného vzoru, CZ, Úřad průmyslového vlastnictví, č. zápisu21409, zapsáno 25.10.2010, 